\title{
Effect of Brewery Size on the Main Process Parameters and Cradle-to-Grave Carbon Footprint of Lager Beer
}

\author{
Alessio Cimini and Mauro Moresi (D) \\ Department for Innovation in the Biological, Agrofood and Forestry Systems, Tuscia University, Viterbo, Italy
}

\author{
Keywords: \\ brewery size \\ carbon footprint \\ glass and PET bottles \\ lager beer \\ sensitivity analysis \\ specific thermal and electric energy \\ consumption
}

Ell Supporting information is linked to this article on the JIE website

\begin{abstract}
Summary
Several carbon footprint (CF) studies have been so far carried out to assess the environmental impact of the brewing industry. In this study, a series of reliable secondary data for small-, medium-, and large-sized breweries were collected and used to develop a simplified model to estimate the cradle-to-grave (C2G) CF of the production of a functional unit consisting of I hectoliter (hL) of lager beer packed in 66-centiliter (glass or polyethylene terephthalate [PET]) bottles. With reference to the typical operating conditions of nine breweries of different size, the C2G CF was found to increase up to $43 \%$ or $45 \%$ either for glass or PET bottles as the brewery size reduced from $10 \times 10^{5}$ to $500 \mathrm{hL}$ per year. Whatever the brewery size, the use of PET instead of glass bottles lowered the beer CF by $2.7 \pm 0.9 \%$. The contribution of the consumer and postconsumer waste disposal phases was found to be significant. Thus, beer makers should pay attention to the recycling ratio of postconsumer packaging in the sales areas. The C2G CF tended to increase linearly with the overall (thermal and electric) energy needed to produce I hL of beer, almost independently of the primary packaging material used. Such a simple and easy-to-measure quantitative indicator might be more than sufficient not only to estimate qualitatively the environmental burden of beer production, but also to identify which mitigation opportunities might be explored or to prioritize primary data collection efforts to refine CF calculation.
\end{abstract}

\section{Introduction}

Beer is a widely consumed alcoholic beverage across the world (about 1.93 billion hectoliters ${ }^{1}$ [hL] in 2015: www. statista.com/statistics/270275/worldwide-beer-production/), with a beer consumption per capita on the order of 27 liters (L) per year. In Italy, the overall production of beer was about 13.521 million hL in 2014 (Assobirra 2014). Such a production was due to a few industrial breweries, each one producing over than 1.5 million $\mathrm{hL}$ of beer per year ( $\mathrm{yr}$ ), a small number of medium-sized breweries with capacity in the range of 150,000 to $1,200,000 \mathrm{hL} / \mathrm{yr}$ (www.beverfood.com), and over $637 \mathrm{craft}$ breweries (including micro-breweries and brewpubs), located mainly in the North of Italy (www.microbirrifici.org/). The great majority of craft breweries have a very low capacity of about $622 \mathrm{hL} / \mathrm{yr}$ and just a few produce up to $10,000 \mathrm{hL} / \mathrm{yr}$ (Ravelli and Pedrini 2015). In toto, their overall production is circa $378,000 \mathrm{hL} / \mathrm{yr}$, that is, $2.8 \%$ of the national beer production (Assobirra 2014). In contrast, with 4,269 breweries, the U.S. craft beer industry now represents $12 \%$ of market share of the total beer market (Kell 2016). Such a growing demand for craft beer is undoubtedly related to its typical

Conflict of interest statement: The authors have no conflict to declare.

Address correspondence to: Mauro Moresi, Dipartimento per la Innovazione nei sistemi Biologici, Agroalimentari e Forestali (DIBAF), Università della Tuscia, Via S. C. de Lellis, 01100 Viterbo, Italy. Email: moresi@unitus.it, Web: https://moodle.unitus.it/moodle/libretti/dettagli_docente.php?iddocente=522

(C) 2017 by Yale University

DOI: $10.1111 /$ jiec. 12642

Editor managing review: Annie Levasseur

Volume 22, Number 5 